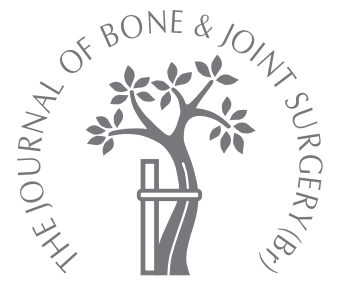

D. Karataglis,

G. Kapetanos,

A. Lontos,

A. Christodoulou,

J. Christoforides,

J. Pournaras

From the Aristotelian

University of

Thessaloniki,

"G. Papanikolaou"

General Hospital,

Thessaloniki, Greece

D. Karataglis, MD,

Orthopaedic Surgeon

A. Christodoulou, MD

Associate Professor

II. Pournaras, MD, Professor

First Orthopaedic Department

Aristotelian University of

Thessaloniki, “G.

Papanikolaou" General

Hospital, 57010 Exohi,

Thessaloniki, Greece.

G. Kapetanos, MD, Professor Third Orthopaedic Department Aristotelian University of Thessaloniki, "Papageorgiou" Hospital, 54629 Efkarpia,

Greece.

A. Lontos, PhD, Mechanical Engineer

Laboratory for Machine Tools

and Manufacturing

Engineering

School of Mechanical

Engineering, Aristotelian

University of Thessaloniki,

Thessaloniki, Greece.

In J. Christoforides, MD,

Associate Professor

Second Orthopaedic

Department

Aristelian University of

Thessaloniki, "G. Gennimatas"

Hospital, Thessaloniki, Greece.

Correspondence should be sent to Dr D. Karataglis; e-mail: dkarataglis@yahoo.gr

(C)2006 British Editorial Society of Bone and Joint Surgery doi:10.1302/0301-620X.88B5. $17422 \$ 2.00$

$J$ Bone Joint Surg $[\mathrm{Br}]$ 2006;88-B:692-5.

Received 15 November 2005 Accepted 19 January 2006

\title{
The role of the dorsal vertebral cortex in the stability of transpedicular screws
}

\author{
A BIOMECHANICAL STUDY IN HUMAN CADAVERIC VERTEBRAE
}

\begin{abstract}
The aim of this biomechanical study was to investigate the role of the dorsal vertebral cortex in transpedicular screw fixation. Moss transpedicular screws were introduced into both pedicles of each vertebra in $\mathbf{2 5}$ human cadaver vertebrae. The dorsal vertebral cortex and subcortical bone corresponding to the entrance site of the screw were removed on one side and preserved on the other. Biomechanical testing showed that the mean peak pull-out strength for the inserted screws, following removal of the dorsal cortex, was $956.16 \mathrm{~N}$. If the dorsal cortex was preserved, the mean peak pullout strength was $1295.64 \mathrm{~N}$. The mean increase was $339.48 \mathrm{~N}(26.13 \% ; p=0.033)$. The bone mineral density correlated positively with peak pull-out strength.

Preservation of the dorsal vertebral cortex at the site of insertion of the screw offers a significant increase in peak pull-out strength. This may result from engagement by the final screw threads in the denser bone of the dorsal cortex and the underlying subcortical area. Every effort should be made to preserve the dorsal vertebral cortex during insertion of transpedicular screws.
\end{abstract}

Transpedicular screws were introduced by Roy-Camille, Sailant and Mazel in the 1960s and were popularised in the 1970 s. ${ }^{1}$ Since then they have been used extensively in the management of vertebral fractures, spinal tumours, metastatic disease, deformity and degenerative disorders in both the lumbar and thoracic spine. ${ }^{2-5}$ The use of transpedicular screws and rods allows adequate three-dimensional control of each motion segment and allows rigid spinal fixation, ${ }^{6,7}$ which is an important factor in promoting faster incorporation of the graft and solid spinal fusion. ${ }^{8}$

Stability of the overall construct is an important factor. It relies on the quality of purchase achieved in the interface between the screw and the bone. A number of factors, including the design characteristics of the implant, the quality of the host bone and surgical technique, have been shown to influence the purchase of the screw and consequently, the clinical outcome. ${ }^{9-23}$

In the traditional technique, removal of the dorsal vertebral cortex and the underlying subchondral bone at the entrance point for the screw is advocated in an effort to ensure safe placement. ${ }^{24-26}$

The aim of this study was to investigate the role of the dorsal vertebral cortex, by measuring pull-out strength in an in vitro biomechanical study on human cadaver vertebrae.

\section{Materials and Methods}

A total of 25 human cadaver lumbar vertebrae were harvested within 24 hours of death from 14 donors, eight male and six female, with a mean age of 59 years (18 to 92). We used five L2, 14 L3 and six L4 vertebrae, all of which were dissected free of soft-tissue attachments. Anteroposterior and lateral radiographs were obtained in order to exclude any underlying bony pathology that might have affected the results. The vertebrae were sealed and stored at $-20^{\circ} \mathrm{C}$ until required.

Prior to freezing the bone mineral density (BMD) was evaluated by dual energy x-ray absorptiometry (DEXA) using the Lunar DPX Plus DEXA meter (Lunar Radiation Co., Madison, Wisconsin). Anteroposterior scans were obtained by submerging each vertebra in 20 $\mathrm{cm}$ of water at room temperature, to simulate the soft-tissue sleeve. The BMD was calculated in $\mathrm{g} / \mathrm{cm}^{2}$.

The specimens were left to thaw at room temperature for 12 hours before any further manipulation. Moss transpedicular screws (Biedermann Motech GmbH, Schwenningen, Germany) were used. They were $50 \mathrm{~mm}$ long, barrel-shaped and had an outer screw diameter of $6 \mathrm{~mm}$, an inner screw diameter of $4 \mathrm{~mm}$ and a thread pitch (distance between the two screw threads) of $2 \mathrm{~mm}$. The entrance site was the 


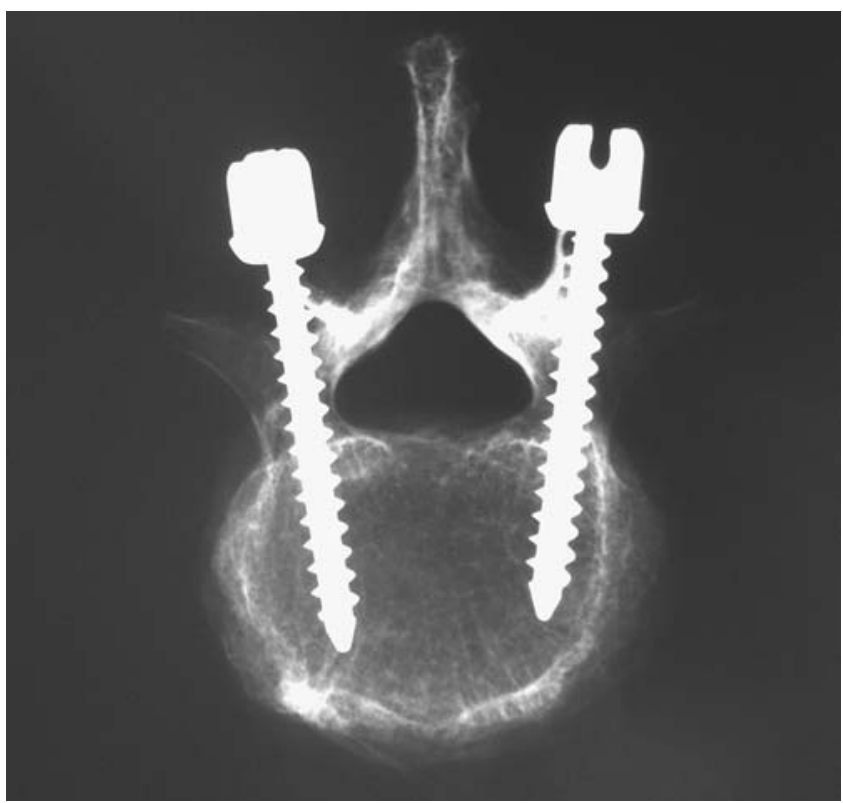

Fig. 1

Radiograph following insertion of transpedicular screws and the resected dorsal cortex.

junction of the horizontal line that bisects the transverse process and the longitudinal line passing just lateral to the superior articular facet. On one side of each vertebra, the dorsal cortex and subcortical bone at the site of entrance of the screw was removed, using a bone rongeur with a diameter approximately equal or bigger to the outer diameter of the transpedicular screw, prior to probing and insertion. On the contralateral side an identical entry point and insertion technique of the screw was used, but the dorsal cortex and subcortical bone were preserved. Anteroposterior and lateral radiographs were obtained following transpedicular screw insertion, in order to verify accurate screw placement (Fig. 1). Each vertebra was individually potted in Serifix cold moulding polyester resin (Struers A/S, Copenhagen, Denmark). We took care to ensure that intrusion of resin into the screw/vertebra construct was avoided, as suggested by Pfeiffer et al. ${ }^{27}$

Mechanical testing was performed using pneumohydraulic testing apparatus, based on a DNC-100 Festo double acting cylinder (Festo AG, Esslingen, Germany). The potted vertebrae were mounted on the testing apparatus with the aid of a specially designed jig which was adjustable so as to allow alignment of the pull-out force with the longitudinal axis of the screw. A loading rate of $50 \mathrm{~N} / \mathrm{s}$ was applied from zero to failure. Failure was defined as the point at which the load peaked (the peak pullout strength) and then abruptly decreased, with increasing displacement. Load was measured with a 9271-A dynamometer (Kistler Instrumente AG, Winterthur, Switzerland), while displacement was assessed using a TT20 extensometer (Brown \&
Sharpe Tesa SA, Renens, Switzerland). Data were collected at a rate of $100 \mathrm{~Hz}$ using Lab View 5.1 software (National Instruments Co, Austin, Texas). A load deflection curve was generated for each screw.

Statistical analysis was performed using the SPSS 10.0 (SPSS Inc., Chicago, Illinois) and STATA 6.0 (StataCorp LP, College Station, Texas) software packages. An unpaired Student's $t$-test was used to compare quantitative variables between the two sides of each vertebra. Scatter diagrams were plotted in order to calculate the correlation between $\mathrm{BMD}$ and peak pullout strength. For both techniques the regression equation $(\mathrm{y}=\alpha+\beta \mathrm{x})$ was used and the significance level was set at $\mathrm{p}<0.05$.

\section{Results}

In the 25 lumbar vertebrae, the mean BMD was 0.939 $\mathrm{g} / \mathrm{cm}^{2}(0.508$ to 1.269 ; SD $0.192 ; 95 \%$ confidence interval (CI) 0.86 to 1.02 ). The screws were successfully inserted within the pedicles to a depth of $60 \%$ to $80 \%$ of the vertebral body. Cortical penetration was not noted in either the pedicle or the anterior vertebral body in any of the vertebrae. The mode of failure was a clean pull-out. Of the 25 vertebrae, all of which were tested on both sides, there were 48 cases of failure at the bone/screw interface and two cases of pull-out coupled with fracture of the ipsilateral pedicle.

The mean peak pull-out strength for the screws inserted following removal of the dorsal vertebral cortex was $956.16 \mathrm{~N}(193 \mathrm{~N}$ to $2241 \mathrm{~N}$; SD $493.88 \mathrm{~N} ; 95 \%$ CI 752.30 to 1160.02), while the mean peak pull-out strength for the screws inserted when the dorsal vertebral cortex at the screw insertion site was preserved, was $1295.64 \mathrm{~N}(251 \mathrm{~N}$ to $2434 \mathrm{~N} ; 95 \%$ CI 1049.88 to 1541.40$)$. In all 25 vertebrae the peak pull-out strength when the dorsal vertebral cortex was preserved was greater than on the contralateral side where it had been removed (Fig. 2). The mean increase in the peak pull-out strength offered by preservation of the dorsal cortex was $339.48 \mathrm{~N}$ (24 to 620; SD 182.72). The difference in peak pull-out strength was statistically significant $(\mathrm{p}=0.033)$.

The mean displacement at failure was $2.71 \mathrm{~mm}(0.95$ to 4.78; SD 0.91) when the dorsal vertebral cortex was removed and $3.05 \mathrm{~mm}$ (1.79 to 4.91 ; SD 0.88$)$ when it was preserved. This difference was not statistically significant $(\mathrm{p}=0.193)$. Load/displacement curves were calculated for all the vertebrae (Fig. 3).

Scatter diagrams were plotted for BMD versus peak pullout strength and linear regression analysis was carried out to determine the correlation between BMD and peak pullout strength when the dorsal cortex was removed, as well as when it was retained. The regression line analysis showed that BMD was highly correlated with peak pull-out strength in both cases $\left(\mathrm{R}^{2}: 0.626\right.$ and $\mathrm{R}^{2}: 0.732$, respectively; $\mathrm{p}<0.001$ ).

The regression equations $(y=\alpha+\beta x)$ for BMD and peak pull-out strength were: 


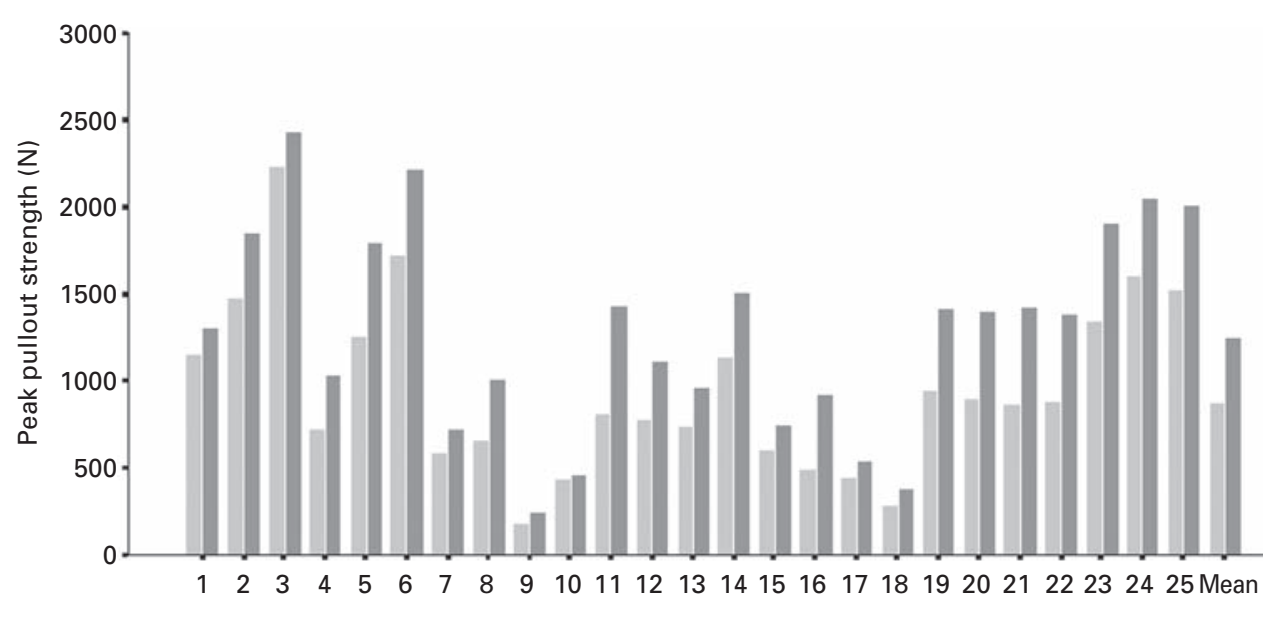

Fig. 2

Histogram showing peak pull-out strength when dorsal vertebral cortex was preserved (dark bars) and removed (light bars).

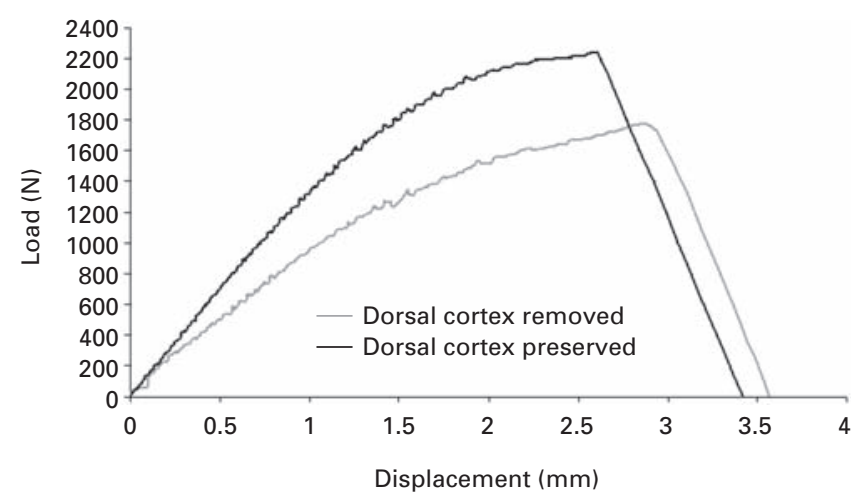

Fig. 3

A typical load-displacement curve.

$y=-950.0+203.0 x(x / 0.10)$ when the dorsal cortex was removed

and

$\mathrm{y}=-1189.4+264.8 \mathrm{x}(\mathrm{x} / 0.10)$ when the cortex was preserved.

\section{Discussion}

The use of transpedicular screws has become increasingly popular in surgery of the spine. Mechanical failures such as bending or breakage of the screws and disassociation of the junction between the pedicle screw and the metal rods joining them can occur, $, 928,29$ while screws may also loosen, migrate or pull out. ${ }^{1,2,8}$

Improvements in design of implants and in surgical technique aim to decrease the rate of failure of the implant, especially in osteoporotic bone. Several studies have examined the effect of factors such as quality of the host bone, screw size, the depth of penetration of the screw, the angle of insertion and the role of preparation of the screw hole in the quality of purchase achieved at the screw/bone interface. ${ }^{10,14,15,18,22,30-33}$ In these studies, decreased BMD has been shown to reduce the quality of fixation, ${ }^{14,15,18,30,31}$ while increase in the size of the screw and the depth of penetration, within certain limits, has been shown to improve it. ${ }^{10,22,32,33}$ The pedicle contributes approximately $80 \%$ of the caudocephalad stiffness and approximately $60 \%$ of the overall pull-out strength of each transpedicular screw. ${ }^{32}$ Engagement of the anterior cortex offers a 30\% increase in pull-out strength, ${ }^{16,17,34}$ while screw coupling and angulation have also been shown to enhance construct stability. ${ }^{19,21,35}$

In traditional techniques, preparation of the entrance point of the screw includes resection of part of the posterior cortex, with the use of a burr or a ronguer in an effort to improve safe insertion of the screw. ${ }^{24-26}$ When extensive resection of the posterior elements is required, this could lead to visualisation of the pedicle 'end-on', prior to screw insertion. ${ }^{26}$ The extent to which the dorsal vertebral cortex contributes to transpedicular screw stability has not previously been adequately investigated. ${ }^{29,34}$

Daftari et $\mathrm{al}^{12}$ have demonstrated with experiments in both calf vertebrae and plastic vertebral bodies, that preservation of the dorsal cortex is desirable, in order to achieve better fixation. Cotterill et $\mathrm{al}^{36}$ have shown that considerable differences exist between calf and human vertebrae and therefore the results obtained from experiments in calf vertebrae and plastic vertebral bodies should be interpreted cautiously.

Our study investigated the exact role of the preservation of the dorsal vertebral cortex in the stability of the transpedicular screw. We used human cadaver vertebrae with a wide range of BMD in an effort to obviate the previously mentioned shortcomings. We have shown that the dorsal 
vertebral cortex contributes $26.13 \%$ of the overall pull-out strength at the screw/bone interface.

Moran et $\mathrm{al}^{20}$ and Hirano et $\mathrm{al}^{32}$ have shown that trabecular bone situated in the centre of the pedicle is surrounded by a layer of subcortical bone with a greater BMD, which in turn is enveloped by a shell of cortical bone. The BMD significantly increases from the centre to the outside and this increase is more profound in normal compared with osteoporotic bone. ${ }^{32}$ Purchase of the screw in denser subcortical bone is desirable in order to increase its stability. ${ }^{33}$ This is why increased screw size and pedicle fill are believed to positively affect the overall fixation stiffness. ${ }^{10}$ This is also the rationale behind the use of polymethylmethacrylate, injectable bone cement or expansile screws, in an effort to improve or augment screw purchase, especially in osteoporotic vertebrae and revision surgery. ${ }^{22,37-42}$ We believe that preservation of the dorsal cortex increases the overall pull-out strength at the screw/bone interface by a similar mechanism with engagement by the final screw threads in the denser bone of the dorsal cortex and the underlying subcortical area. Our results also corroborate findings from previous studies, suggesting that osteoporosis has an adverse effect in the purchase of transpedicular screws. ${ }^{14,15,18,30,31}$

The dorsal vertebral cortex should be preserved during insertion of transpedicular screws as this may considerably improve the overall stability of the construct in both osteoporotic and normal bone.

No benefits in any form have been received or will be received from a commer cial party related directly or indirectly to the subject of this article.

\section{References}

1. Roy-Camille R, Sailant G, Mazel C. Internal fixation of the lumbar spine with pedicle screw plating. Clin Orthop 1986;203:7-17.

2. Blauth $\mathbf{M}$, Tscherne $\mathbf{H}$, Haas $\mathbf{N}$. Therapeutic concept and results of operative treatment: acute trauma of the thoracic and lumbar spine. J Orthop Trauma 1987;1:240-52.

3. Gurr KR, McAfee PC, Shih CM. Biomechanical analysis of anterior and posterior instrumentation systems following corpectomy: a calf spine model. J Bone Joint Surg [Am] 1988;70-A:1182-91

4. Gurr KR, McAfee PC, Shih CM. Biomechanical analysis of posterior instrumentation systems following laminectomy: an unstable calf spine model. J Bone Joint Surg [Am] 1988;70-A:680-91.

5. Katonis P, Kontakis GM, Loupasis GA, et al. Treatment of unstable thoracolumbar and lumbar spine injuries using Cotrel-Dubousset instrumentation. Spine 1999;24: 2352-7.

6. Hitchon PW, Brenton MD, Black AG, et al. In vitro biomechanical comparison of pedicle screws, subliminal hooks and subliminal cables. J Neurosurg 2003;99 (1 Suppl):104-9.

7. Panjabi MM. Biomechanical evaluation of spinal fixation devices: I. conceptual framework. Spine 1988;13:1129-34

8. Sandén B, Olerud C, Petrén-Mallmin M, Johansson C, Larsson S. The significance of radiolucent zones surrounding pedicle screws: definition of screw loosening in spinal instrumentation. J Bone Joint Surg [Br]2004;86-B:457-61.

9. Barber JW, Boden SD, Ganey T, Hutton W. Biomechanical study of lumbar pedicle screws: does convergence affect axial pullout strength? J Spinal Disord 1998;11: 215-20.

10. Brantley AGU, Mayfield JK, Koeneman JB, Clark KR. The effects of pedicle screw fit: an in-vitro study. Spine 1994;19:1752-8.

11. Chapman JR, Harrington RM, Lee KM, et al. Factors affecting the pullout strength of cancellous bone screws. J Biom Eng 1996;118:391-8.

12. Daftari TK, Horton WC, Hutton WC. Correlations between screw hole preparation, torque of insertion, and pullout strength for spinal screws. J Spinal Disord 1994;7 $139-45$.
13. George DC, Krag MH, Johnson CC, et al. Hole preparation techniques for transpedicle screws: effect on pull-out strength from human cadaveric vertebrae. Spine 1991;16:181-4.

14. Hadjipavlou AG, Nicodemus CL, al-Hamdan FA, Simmons JW, Pope MH. Correlation of bone equivalent mineral density to pull-out resistance of triangulated pedicle screw construct. J Spinal Disord 1997;10:12-19.

15. Halvorson TL, Kelley LA, Thomas KA, Whitecloud TS 3rd, Cook SD. Effects of bone mineral density on pedicle screw fixation. Spine 1994;19:2415-20.

16. Krag MH, Beynnon BD, Pope MH, DeCoster TA. Depth of insertion of transpedicular vertebral screws into human vertebrae: effect upon screw-vertebrae interface strength. J Spinal Disord 1989;1:287-94.

17. Krag MH, Van Hal ME, Beynnon BD. Placement of transpedicular vertebral screws close to anterior vertebral cortex: description of methods. Spine 1989;14:879-83.

18. Kumano K, Horabayashi S, Ogawa Y, Aota Y. Pedicle screws and bone mineral density. Spine 1994;19:1157-61.

19. McKinley TO, McLain RF, Yerby SA, et al. Characteristics of pedicle screw loading: effect of surgical technique on intravertebral and intrapedicular bending moments. Spine 1999;24:18-25

20. Moran JM, Berg WS, Berry JL, Geiger JM, Stefee AD. Transpedicular screw fixation. J Orthop Res 1989;7:107-14

21. Ruland CM, McAfee PC, Warden KE, Cunningham BW. Triangulation of pedicular instrumentation: a biomechanical analysis. Spine 1991;16(6 Suppl):270-6.

22. Wittenberg RH, Lee KS, Shea M, White AA 3rd, Hayes WC. Effect of screw diameter, insertion technique, and bone cement augmentation of pedicular screw fixation strength. Clin Orthop 1993;296:278-87.

23. Zdeblick TA, Kunz DN, Cooke ME, McCabe R. Pedicle screw pullout strength correlation with insertional torque. Spine 1993;18:1673-6.

24. Rinella AS, Kim YJ, Lenke LG. Posterior spinal instrumentation techniques for spinal deformity. In Bradford DS, Zdeblick TA, eds. The spine. Second ed. Philadelphia: Lippincott, Williams \& Wilkins, 2004:231-46.

25. Albert TJ, Jones AM, Balderston RA. Spinal Instrumentation. In: Rothman RH Simeone FA, eds. The spine. Vol 2. Third ed. Philadelphia: W. B. Saunders Company, 1992:1777-800.

26. Krag MH. Biomechanics of thoracolumbar spinal fixation. In: Thalgott JS, Aebi M eds. Manual of internal fixation of the spine. Philadelphia: Lippincott-Raven Publishers, 1996:23-42

27. Pfeiffer M, Gilbertson LG, Goel V, et al. Effect of specimen fixation method on pullout tests of pedicle screws. Spine 1996;21:1037-44.

28. Hadjipavlou AG, Enker P, Katzman S, Silver J. The causes of failure of lumbar trans pedicular spinal instrumentation and fusion: a prospective study. Int Orthop 1996;20:35-42

29. Katonis $\mathbf{P}$, Christoforakis $\mathbf{J}$, Aligizakis AC, et al. Complications and problems related to pedicle screw fixation of the spine. Clin Orthop 2003;411:86-94.

30. Soshi S, Shiba R, Kondo H, Murota K. An experimental study of transpedicular screw fixation in relation to osteoporosis of the lumbar spine. Spine 1991;16:1335-41.

31. Wittenberg RH, Shea M, Swartz DE, et al. Importance of bone mineral density in instrumented spinal fusions. Spine 1991;16:647-52.

32. Hirano T, Hasegawa K, Takahashi HE, et al. Structural characteristics of the pedicle and its role in screw stability. Spine 1997;22:2504-10.

33. Misenhimer GR, Peek RD, Wiltse LL, Rothman SLG, Widell EH. Anatomic analysis of pedicle cortical and cancellous diameter as related to screw size. Spine 1989; 14:367-72.

34. Weinstein JN, Rydevik BL, Rausching WR. Anatomical and technical considerations of pedicle screw fixation. Clin Orthop 1992;284:34-6.

35. Suzuki T, Abe E, Okuyama K, Sato K. Improving the pullout strength of pedicle screws by screw coupling. J Spinal Disord 2001;14:399-403.

36. Cotterill PC, Kostuik JP, D'Angelo G, Fernie GR, Maki BE. An anatomical comparison of the human and bovine thoracolumbar spine. J Orthop Res 1986;4:298-303.

37. Cook SD, Salkeld SL, Whitecloud TS 3rd, Barbera J. Biomechanical evaluation and preliminary clinical experience with an expansive pedicle screw design. J Spinal Disord 2000;13:230-6.

38. Ikeuchi M, Yamamoto H, Shibata T, Otani M. Mechanical augmentation of the vertebral body by calcium phosphate cement injection. J Orthop Sci 2001;6:39-45.

39. Lotz JC, Hu SS, Chiu DFM, et al. Carbonated apatite cement: augmentation of pedicle screw fixation in the lumbar spine. Spine 1997;22:2716-23.

40. Pfeiffer BA, Krag MH, Johnson C. Repair of transpedicular screw fixation: a biomechanical study comparing polymethylmethacrylate, milled bone and matchstick bone reconstruction. Spine 1994;19:350-3.

41. Sarzier JS, Evans AJ, Cahill DW. Increased pullout strength with vertebroplasty augmentation in osteoporotic spines. J Neurosurg 2002;96(3 Suppl):309-12.

42. Taniwaki Y, Takemasa R, Tani T, Mizobuchi H, Yamamoto H. Enhancement of pedicle screw stability using calcium phosphate cement in osteoporotic vertebrae: in vivo biomechanical study. J Orthop Sci 2003:8:308-14. 